\title{
Climate Engineering Migration Issues and Countermeasure Analysis in the Context of Climate Change
}

\author{
Zhijie Cao \\ Hohai University \\ Nanjing, China \\ caozhijiehh@163.com
}

\author{
Shaojun Chen \\ The National Research Center for Resettlement \\ Hohai University \\ Nanjing, China \\ shaojun_chen@126.com
}

\begin{abstract}
Climate change and its adverse effects caused a large number of migrants, had been become the 21st century challenges for human society. Under climate changing, human has implemented macro and micro climate engineering in response to deteriorating natural living conditions, and a number of growth-promoting climate engineering migrants. By definition and by type of the concept of climate engineering migration, Analyze Climate engineering implementation due to migration secondary impoverishment, and reducing the degree of social adaptation and other influence. To solve the above problem, proposed increasing land compensation rates and investment in land maturation, supporting pillar industries and strengthening post-resettlement support, Developing migrants' sustainable livelihood development capacity, paying attention to special features of social structure to promote the social adaptation of migrants and other suggestions.
\end{abstract}

Keywords- Climate change; Climate engineering; Climate engineering migration; Problems; Countermeasures and proposals

\section{INTRODUCTION}

Climate change and extreme climate events have become a severe challenge facing human society in the 21st century, and resulted in such climatic disasters as accelerated glacier melting, sea level rise, aggravated desertification, blizzard, and alternating droughts and floods, giving rise to extensive "climate migration" [1]. Presently, "climate refugees in many countries and regions have started spontaneous and organized climate migration. To date, about 26 million people in the world have been forced to migrate due to climate change. This number is estimated to be 200 million by 2050" [2]. As a result of global climate change and natural disasters, the scale of global climate migration is expanding [3]. Currently, regions sensitive to climate change are faced with the ordeal of climate change, and it seems quite difficult to respond to disasters arising from climate change. In the two major basic strategies of mitigating and adapting to climate change, population migration is a countermeasure of mankind to the challenge of climate change [4], and is increasingly drawing the attention of policymakers and researchers, but knowledge on climate engineering and population migration remains limited and fragmented [5].
How to base on existing studies, explore and sort out crucial issues, and analyze restrictive factors contributing to climate migration [6]. It is an inevitable and urgent topic to improve people's understanding of the severity of climate engineering migration arising from climatic risks, separate them from the current of economic migration, explore and make clear some important issues concerning climate engineering migration, and analyze their restricting factors.

\section{TYPES AND FORMS OF CLIMATE ENGINEERING}

By reference to the existing research findings of Shi Guoqing, Chen Shaojun and Cao Zhijie et al on climate migration problems arising from climate change[7], and in light of the adaptation or mitigation measures taken in the context of climate change, this article defines climate engineering as the collective term of all engineering measures taken to control and utilize climatic resources, mitigate adverse impacts of climate change on human survival and life, and prevent actual or potential disasters arising from climatic risks. Damages caused by climate change are increasingly serious, and various attempts that can mitigate climate change are increasingly attractive. In view of the increasing shortage of climatic resources and their prominent public features, climate engineering implemented by human to mitigate and adapt to climate change has emerged accordingly, and is divided into macroscopic and microscopic levels.

Macroscopic climate engineering aims to develop and conserve global, regional and local climatic resources to mitigate climate change, which is shown in economic and social planning, layout and management mainly. Microscopic climate engineering means that production and living units (users) develop and utilize required climatic resources under the direction of the macroscopic plan to adapt to the increasingly severe situation of climate change in a region. The essence of climate engineering is to transfer and evade actual or potential climatic risks and disasters by making scientific, rational planning and management, and taking effective measures in order to solve deteriorating climatic, environmental and developmental problems facing mankind, and coordinate mankind with nature. However, the immediate implementation of climate engineering, especially macroscopic climate engineering, will inevitably lead to 
extensive population migration to some extent, giving rise to involuntary climate migration closely associated with climate engineering and related problems.

\section{TYPES OF CLIMATE ENGINEERING MIGRATION IN CLIMATE ENGINEERING}

"Climate migration as people or groups of people leaving hometowns forcedly or forwardly, temporarily or permanently under the influence of climate policies or climate projects when sudden or slow climate change affects their living or subsistence conditions adversely. They may either migrate domestically or internationally" [7].A main type of climate migration is migrants arising from climate engineering implemented to mitigate adverse impacts of climate change on human survival and life, as well as resulting population migration behavior, and social and economical system rebuilding. Climate engineering migration arising from climate change mainly involves involuntary climate migration, which means people or groups of people forced to leave hometowns temporarily or permanently because they are unable to maintain their livelihoods locally, and their vital and property safety is threatened when sudden or slow climate change affects their living or subsistence conditions adversely in order to resist or mitigate adverse impacts from climate change (e.g., drinking water source works, and farmland irrigation and diversion works constructed in dry regions, and coastal shelter forests and flood dams in coastal regions).

"Climate engineering migration refers mainly to involuntary migration for construction to mitigate adverse impacts arising from climate change, and is resettlement of engineering nature. Climate engineering migration if often compulsory, and migrants have no autonomy in whether, when and where to migrate, and are faced with social and economical system rebuilding in another location" [8].

Depending on the shape of acquired land, climate engineering migration can be roughly divided into migration for linear land acquisition and migration for blocky land acquisition; depending on migration mode, climate engineering migration can be divided into local setback, centralized outward relocation, scattered group insertion, etc. Depending on practices of climate engineering in regions with harsh climatic conditions in China, climate engineering migration can be divided roughly into two types - linear or belt-shaped migration with the main resettlement mode of local setback, and migration for blocky land acquisition with the main resettlement mode of local setback or centralized outward relocation.

\section{A. Linear or belt-shaped local setback}

For climate engineering projects implemented in dry northwestern inland regions and low-lying southeastern coastal regions with complex climatic conditions, such as irrigation canals, sea walls and bank revetments, acquired land is mostly linear or belt-shaped, with length ranging from tens to hundreds of kilometers, and width ranging from several to hundreds of meters. Such projects involve numerous administrative units (province-city-countytownship_village — group), but the percentage of acquired land area in each unit (township or village) to its gross land area is small and migration is limited (or even none). Since settlements are evaded where possible during design, migration involved in land acquisition or house demolition is smaller as compared to reservoir and urban construction projects.

\section{B. Migration for blocky land acquisition}

Migration for blocky land acquisition means the relocation and/ reconstruction of (market) towns, industrial and mining enterprises, public institutions, settlements and special facilities, extensive demolition of houses and other buildings, and population migration due to the occupation or inundation of extensive land for large and medium infrastructure construction projects, including reservoirs, hydropower stations, pumping stations, sluices, etc. Acquired land is often large, contiguous and blocky in shape. Projects involving resettlement for blocky land acquisition often involve the large-scale migration of the population of whole villages or townships, and social and economical system rebuilding. In such projects, production and livelihood migration is difficult, complex.

\section{KEY IMPACTS OF CLIMATE ENGINEERING ON MIGRATION AND PROBLEMS}

During climate engineering migration, migrants are faced with both losses in natural and economic capital, and damages of human and social capital. The social impacts of various engineering projects on involuntary migration are so complex, extensive and far-reaching that Michael $\mathrm{M}$ Cernea - former Senior Adviser for Sociology and Social Policy of the World Bank - created the impoverishment risks and reconstruction (IRR) model for involuntary migration [9] to analyze difficulties and risks suffered by migrants.

\section{A. Realistic impacts of climate engineering on migration}

Climate engineering migrants generally suffer a double dilemma in development, namely "secondary impoverishment" and livelihood unsustainability. First, involuntary climate migration areas usually have concentrated poor population, where displaced households are financially weak, and unable to increase production investment and maintain livelihoods, and will eventually suffer secondary impoverishment. On the other hand, most migrants are very likely to enter the vicious cycle of disproportional return on investment and environmental deterioration, so that their livelihoods become unsustainable.

The social adaptability of migrants is reduced. During resettlement, the material living environment can be easily recreated, but the recreation of the spiritual living environment is a chronic or even painful process. The sharp change of livelihood patterns and the living environment will inevitably result in the short-term nonadaptation of migrants to the resettlement area, and the adaptation process will take a long time. They are faced with the passive social and cultural change and can hardly adapt effectively in a short period.

\section{B. Key problems in climate engineering migration}

First, land reallocation and resettlement are difficult. The biggest problem facing climate engineering migrants is their inability to restore livelihoods, especially in the resettlement mode based on agriculture and land. There is often insufficient land available for reallocation in 
resettlement areas, thereby increasing the difficulty of resettlement.

Second, resettlement compensation rates are low, resulting in the conflict between increased difficulty in resettlement area development and reduced state investment. Some large climate engineering projects in some parts of China are associated with water resources, to which China's compensation and supporting policies on reservoir resettlement apply. However, the compensation rate of 16 times the average annual output value of land that has been applied to date can no longer meet actual needs for resettlement.

Third, with the sharp change of livelihood patterns, migrants have an urgent demand for skills training. After the resettlement of climate engineering migrants, their agricultural production pattern has changed radically from rain-fed agriculture to irrigated agriculture and from extensive farming to intensive farming. The temporary non-adaptation arising from livelihood change is perplexing migrants, so that they can hardly deal with production with peace of mind. In face of these sudden changes, migrants are at a loss and expect external support. They should be guided and trained by competent authorities to make them self-reliant and hard-working.

Fourth, the loss of social capital leads to difficulty in social adaptation. During the implementation of climate engineering, migrants are also faced with the risk of being repulsed and marginalized by local officials and residents. Resettlement often leads to the disintegration of migrants' former social networks.

\section{COMMENTS AND SUGGESTIONS ON RESPONSE TO CLIMATE ENGINEERING MIGRATION PROBLEMS}

To evade or mitigate potential social risks arising from involuntary climate migration calls for scientific and rational planning, and active and effective explorations.

\section{A. Increasing land compensation rates and investment in land maturation}

Land is the fundamental condition for migrants' subsistence and the most important means of social security for them. In order to protect farmers' interests, and reduce economic and social costs, it is necessary to change the former principle of "appropriate compensation" for land acquisition to "fair compensation" based on market pricing to increase compensation rates for land acquisition reasonably. In addition, land development in resettlement areas should be strengthened, modern agriculture developed energetically, and agricultural structure transformed to help migrants develop production and get rich as soon as possible.

\section{B. Supporting pillar industries and strengthening post- migration support}

The fundamental issue of migration is the subsequent development of industries after migration. In resettlement areas, pillar and advantaged industries may be developed based on local conditions and resources. For example, protected agriculture, water-saving cultivation, efficient cultivation, and efficient ecological agriculture may be developed through policy support, demonstration and technical services, etc. to increase migrants' operating income. In post-migration support, secondary and tertiary industries should be preferred to agriculture and put under unified planning.

\section{Developing migrants'sustainable livelihood development capacity}

In order to maintain migrants' sustainable livelihood development capacity, favorable internal and external conditions should be available for their sustainable development. In the long run, the government should change their minds, encourage them to rebuild homes and rely on themselves, and improve their production and living abilities through various forms of education. Externally, investment in vocational education and skills training should be increased so that young migrants having not received higher education become skilled as a basis of sustainable livelihood development.

\section{Paying attention to special features of social structure to promote the social adaptation of migrants}

During the social adaptation of migrants in resettlement areas, competent authorities and local governments should pay particular attention to special needs for preserving traditional social structure, and create conditions for them to restore social structure and rebuild social networks [10]. Interactions among migrants should be created within village groups gradually to make them more familiar with one another, mutual aid organizations established within village groups, and social forces mobilized to help and care about climate engineering migrants.

\section{SUMMARY}

In sum, in the foreseeable future, extreme climate events will be more frequent, and climate change and natural disasters will become another drive to population migration. However, since all countries and communities are concentrating on suppressing climate change, topics involving climate engineering migration have not drawn due attention, and measures and cooperation mechanisms for responding to climate engineering migration problems have not been established. Social conflicts and risks that follow will make this situation even worse. In order to respond to such problems and minimize adverse impacts on global sustainable development, regions and countries that are likely to be affected must take actions immediately, establish effective adaptation mechanisms at the regional, national and international levels, and make active explorations on corresponding policies and measures.

\section{ACKNOWLEDGMENT}

This article was prepared under the Foundation project: "Minority Involuntary Hydropower Resettlement Social and Cultural Adaptation Research” (No.: 14CSH047) and the "Discipline Cross Resettlement Project Research" (No.: 13\&ZD172) were supported by the National Social Science Fund of China; Also supported by the China Postdoctoral Science Foundation (No.: 2014M561563), the Fundamental Research Funds for the Central Universities (No.: 2014B09814)", and is an interim output thereof.

\section{REFERENCES}

[1] Kniveton D K, Schmidt-Verkerk, et al. Climate Change and Migration: Improving Methodologies to Estimate Flows [J]. 
Geneva, International Organization for Migration - Migration Research Series, 2008:33.

[2] Jifeng Li. Forced migration of the climate refugees [N]. Literature Report, (2010-01-07).

[3] Myers N. Environmental refugees: An emergent security issue [C]. 13th Economic Forum, Prague, May 2005.

[4] Shi Guoqing ed. Ready for Climate Change Related to Immigration[J]. Science, 2011, 334(10): 456-457.

[5] Etienne Piguet, Antoine Pécoud, Paulde Guchteneire. Centre on Migration, Policy and Society[J]. Working Paper University of Oxford, 2010,No 79

[6] Stark O, Bloom D E. The New Economics of Labor Migration [J]. American Economic Review 1985, 75: 175-1789.
[7] Cao Zhijie, Chen Shaojun. Migration Mechanism of Climate Migrants and Analysis of Relevant Concepts, J. EI. Advanced Materials Research Vols.518-523 (2012): 5070-5074.

[8] Chen Shaojun, Cao Zhijie. The Concept and Types of Climate Migration from the Perspective of Climate Risks, J. EI. Advanced Materials Research Vols.610-613 (2013): 748-751.

[9] Michael M. Seney. World Bank Policy Research and experience Migration and Development[M]. Nanjing: Hohai University Press, 1996 : 111-113.

[10] Castles S. Environmental change and forced migration: making sense of the debate [J]. New Issues in Refugee Research - UNHCR Research Paper, 2002, 36(4):70-73. 